\title{
BMJ Global Health Adequacy of clinical trial evidence of metformin fixed-dose combinations for the treatment of type 2 diabetes mellitus in India
}

\author{
Valerie Evans, ${ }^{1,2}$ Peter Roderick, ${ }^{3}$ Allyson M Pollock ${ }^{3}$
}

\begin{abstract}
To cite: Evans V, Roderick P, Pollock AM. Adequacy of clinical trial evidence of metformin fixed-dose combinations for the treatment of type 2 diabetes mellitus in India. BMJ Glob Health 2018;3:e000263. doi:10.1136/ bmjgh-2016-000263
\end{abstract}

Handling editor Seye Abimbola

Received 5 December 2016 Revised 15 September 2017 Accepted 21 September 2017

Check for updates

${ }^{1}$ School of Social and Political Science, University of Edinburgh, Edinburgh, UK

${ }^{2}$ Department of Biostatistics and Epidemiology, School of Public Health and Health Sciences, University of Massachusetts Amherst, Amherst,

Massachusetts, USA

${ }^{3}$ Institute of Health and

Society, Newcastle University, Newcastle, UK

Correspondence to Professor Allyson M Pollock; allyson.pollock@ncl.ac.uk

\section{ABSTRACT}

There is growing national and international concern about the drug regulatory system in India. Parliamentary reports have highlighted the presence of high numbers of unapproved medicines and irrational combinations of both approved and unapproved drugs in the Indian marketplace. Fixed-dose combinations (FDCs) are a peculiar feature of the Indian pharmaceutical landscape. Although metformin is a first-line treatment, FDCs for diabetes in India account for two-thirds of all diabetes medicine sales, and some have not been approved by the Central Drugs Standard Control Organization (CDSCO). This study examines the basis of efficacy and safety of top-selling metformin FDCs in India against four WHO criteria from clinical trials guidelines for the approval of FDCs. Data from a commercial drug sales database (PharmaTrac) were combined with searches through published literature, clinical trial registries, and published and unpublished trial websites of metformin FDCs in adults with type 2 diabetes mellitus. Five metformin FDCs in India from November 2011 to October 2012 accounted for $80 \%$ of all metformin FDC sales by value and volume. Although all five had obtained CDSCO approval, three had been sold and marketed prior to receiving this approval. Evaluation of published and unpublished clinical trials of these five FDCs found none provided robust evidence of safety and efficacy for the treatment of type 2 diabetes. Recommendations are made for publishing evidence that underpins drug approvals, marketing bans, greater transparency through updated clinical trials databases and legislative reform in order to prevent irrational FDCs from entering the market.

\section{INTRODUCTION}

Clinical trials are a crucial step in the development of new medicines. They are required by national drug regulatory agencies to ensure medicines are safe and effective for use in a human population. Every country is responsible for maintaining a stringent approval system to control the entry and distribution of medicines within their borders. Typically, this requires the successful completion and adequate presentation of results from phase I through phase III clinical trials, from preliminary safety data to the analysis

\section{Key questions}

What is already known about this topic?

- Although metformin is a first-line treatment for diabetes, fixed-dose combinations (FDCs) in India account for the majority of diabetes medicine sales.

- The five top-selling FDCs account for 500 brands; multinational corporations manufacture all five FDCs.

- Different dosages of three of the five top-selling metformin FDCs were banned by the government in March 2016 in its ban of 344 irrational FDCs.

What are the new findings?

- A review of both published and unpublished clinical trials for the five top-selling metformin FDCs in India found only one study evaluating the efficacy and safety of a metformin FDC versus concomitant use of the component drugs as singledrug formulations; it was underpowered and of poor quality.

- None of the 25 clinical trials for the five top-selling FDCs met all four selected criteria from WHO guidelines for the conduct of trials and approval of FDC medicines.

of safety and efficacy results from extensive human trials. The US Food and Drug Administration (FDA) approves approximately 40 new medicines for the US market each year through this process. ${ }^{1}$ Drug approval packages for new drugs, which include a full review of submitted materials for approved drugs, are available through the FDA's website. India approves more than 100 new medicines a year but does not publish data on submitted applications or summaries of approved medicines, and concerns have been raised about the safety and efficacy around medicine approvals in the absence of appropriate clinical trials. ${ }^{2-5}$

Over 60 million people have been diagnosed with type 2 diabetes mellitus in India, which has been described as "the diabetes 


\section{Key questions}

\section{Recommendations for policy}

- The safety and efficacy considered by the Central Drugs Standard Control Organization in approving the five top-selling metformin FDCs for the treatment of type 2 diabetes mellitus in India should be published immediately. If the evidence does not extend beyond the trials reviewed in this paper, those FDCs should be banned immediately. If that evidence includes the results of trials not reviewed in this paper, but those trials do not meet the WHO standards used here for evaluation, those FDCs should be banned.

- Clinical trial databases should be constantly updated with both protocols and outcomes in order to improve transparency of trial data; evidence underpinning drug approvals should be published.

- Legislation on clinical trial and data submission requirements for FDCs should be revised and aligned with WHO recommendations in order to prevent irrational FDCs from entering the market and to improve transparency.

- An urgent review of FDCs should be mandated by the Indian Parliament.

capital of the world'. ${ }^{6}$ Given the constant monitoring and rapid adjustment of treatment regimens required to maintain adequate glycaemic control, metformin fixeddose combinations (FDCs) are not recommended by national or international treatment guidelines. Nevertheless, the Central Drugs Standard Control Organization (CDSCO), India's drug regulator, has given approval for 52 FDC formulations for type 2 diabetes, which in turn has given rise to more than 500 marketed brands of metformin FDCs. In contrast, only two metformin FDCs are approved in the USA, one in Australia, and none in either the UK or Canada (figure 1). ${ }^{3}$ Twenty-seven metformin FDCs were included in the Indian government's ban of 344 unapproved FDCs in March 2016 as having 'no therapeutic justification' following consideration of nearly 6000 unapproved FDCs by an expert committee (see online supplementary table 1 ). ${ }^{2}$ The ban was lifted in December 2016 by the Delhi High Court and was upheld by the Supreme Court in December 2017.78 The Supreme Court required the Drugs Technical Advisory Board to consider the banned drugs (except those approved before 1988) and to submit a report within 6 months.
One of the primary arguments for prescribing FDCs for treatment of type 2 diabetes is improved adherence to treatment due to convenience. ${ }^{9}{ }^{10}$ While some studies suggest FDCs are associated with better adherence than concomitant single-drug formulations (SDFs), they should only be considered when the patient has been stable on a regimen of concomitant SDFs for an extended period of time. ${ }^{11-14}$ Glucose levels fluctuate and treatment adjustments are often needed, but such adjustments are particularly difficult when using FDCs because doses are fixed. Regardless, the convenience of FDCs should not trump efficacy.

The availability of irrational or inadequately tested medicines puts the safety of the public at risk. It is important to ensure that those medicines that are available on the market have been approved after examination for safety and efficacy through the implementation of appropriately designed and analysed clinical trials. This work is an evaluation of the clinical evidence on the safety and efficacy of the most common metformin FDCs sold for treating type 2 diabetes in India.

\section{GATHERING THE LEGAL EVIDENCE Indian rules}

Drugs in India are regulated by the Drugs and Cosmetics Act 1940 and the Drugs and Cosmetics Rules 1945, both of which have been amended many times. Imports and marketing of new drugs are controlled nationally by CDSCO, while manufacture, distribution and sale of drugs are the responsibility of the States. 'New drugs' as a category of 'drugs' was first introduced into the Rules in 1952, and FDCs were expressly mentioned as a specific subcategory of new drugs in 1988. Part X-A and Schedule Y of the Rules-initially inserted in 1988 and significantly revised in 2005 - set the requirements for manufacturing and importing new drugs, including FDCs, for the purposes of conducting clinical trials or marketing (table 1$) \cdot{ }^{15}$ CDSCO must give permission before manufacture and import for these purposes. New drugs, including FDCs, cease to be considered 'new drugs'-and so no longer need CDSCO approval for marketing-4years after their first approval. A duty on the regulator to be satisfied before approval that new

Figure 1 Timeline of important events concerning the five top-selling metformin fixed-dose combinations in India. CDSCO, Central Drugs Standard Control Organization; US FDA, US Food and Drug Administration. 
Table 1 Extracts from the opening paragraphs of Schedule $\mathrm{Y}$ in 1988 and in 2005, comparing the provisions on phase II, III and IV trials as they relate to numbers of trial subjects and centres ${ }^{15}$

\begin{tabular}{|c|c|c|}
\hline Trial phase & 1988 Schedule $Y$ & 2005 Schedule Y \\
\hline Phase II & $\begin{array}{l}\text { 'Normally } 10-12 \text { patients should be studied at } \\
\text { each dose level. These studies are usually limited } \\
\text { to } 3-4 \text { centres...' }\end{array}$ & $\begin{array}{l}\text { 'Studies in Phase II should be conducted in a group of } \\
\text { patients who are selected by relatively narrow criteria } \\
\text { leading to a relatively homogeneous population. These } \\
\text { studies should be closely monitored... If the application } \\
\text { is for conduct of clinical trials as a part of multi-national } \\
\text { clinical development of the drug, the number of sites and the } \\
\text { patients as well as the justification for undertaking such trials } \\
\text { in India shall be provided to the Licensing Authority'. }\end{array}$ \\
\hline Phase III & $\begin{array}{l}\text { 'If the drug is already approved/marketed in } \\
\text { other countries, phase III data should generally } \\
\text { be obtained on at least } 100 \text { patients distributed } \\
\text { over } 3-4 \text { centres primarily to confirm the } \\
\text { efficacy and safety of the drug in Indian patients } \\
\text { when used as recommended in the product } \\
\text { monograph for the claims made. If the drug is } \\
\text { a new drug substance discovered in India, and } \\
\text { not marketed in any other country, phase III } \\
\text { data should be obtained on at least } 500 \text { patients } \\
\text { distributed over } 10-15 \text { centres'. }\end{array}$ & $\begin{array}{l}\text { '(iii) For new drugs approved outside India, Phase III studies } \\
\text { need to be carried out primarily to generate evidence of } \\
\text { efficacy and safety of the drug in Indian patients when } \\
\text { used as recommended in the prescribing information. } \\
\text { Prior to conduct of Phase III studies in Indian subjects, } \\
\text { Licensing Authority may require pharmacokinetic studies } \\
\text { to be undertaken to verify that the data generated in Indian } \\
\text { population is in conformity with the data already generated } \\
\text { abroad. } \\
\text { (iv) If the application is for the conduct of clinical trials as a } \\
\text { part of multi-national clinical development of the drug, the } \\
\text { number of sites and patients as well as the justification for } \\
\text { undertaking such trials in India should be provided to the } \\
\text { Licensing Authority along with the application'. }\end{array}$ \\
\hline Phase IV* & $\begin{array}{l}\text { 'In addition, data on adverse drug reactions } \\
\text { observed during clinical use of the drug should } \\
\text { be collected in 1000-2000 patients...' }\end{array}$ & $\begin{array}{l}\text { 'Post Marketing trials are studies (other than routine } \\
\text { surveillance) performed after drug approval and related } \\
\text { to the approved indication(s). These trials go beyond the } \\
\text { prior demonstration of the drug's safety, efficacy and dose } \\
\text { definition. These trials may not be considered necessary at } \\
\text { the time of new drug approval but may be required by the } \\
\text { Licensing Authority for optimising the drug's use. They may } \\
\text { be of any type but should have valid scientific objectives. } \\
\text { Phase IV trials include additional drug-drug interaction(s), } \\
\text { dose-response or safety studies and trials designed to } \\
\text { support use under the approved indication(s), for example, } \\
\text { mortality/morbidity studies, epidemiological studies etc'. }\end{array}$ \\
\hline
\end{tabular}

*In 1988, phase IV trials were not specifically mentioned in Schedule Y: the 1988 text above is a continuation of the 1988 Schedule $Y$ text for phase III trials.

drugs, including FDCs, are safe and effective was only imposed in 2001. ${ }^{16}$

\section{Clinical trial requirements}

Clinical trials must be carried out in India on 'new drug substances discovered in India' from phase I or from phase III if 'discovered' outside India. As shown in table 1, the 1988 rules specified the minimum numbers and ranges for trial participants and sites, but these were amended and downgraded in $2005 .^{15}$

\section{FDC data submission requirements}

The data submission requirements for an FDC depend on which one of four FDC categories in Appendix VI of Schedule Y the FDC in question falls into: (1) one or more of the active ingredients is a new drug; (2) active ingredients already approved or marketed individually are combined for the first time; (3) already marketed but a change in active ingredient ratios is made; and (4) active ingredients concomitantly have been used for a particular indication for an extended period of time (a claim of convenience). ${ }^{15}$ These requirements and categories have been analysed previously, highlighting poor drafting and the downgrading of the rules in $2005 .{ }^{16}$

It is impossible to know what clinical evidence is before the regulator when it decides to approve an FDC for marketing for three reasons. First, although CDSCO publishes a list of FDCs that have been given marketing approval, no information is publicly available on which FDC category any particular approved FDC falls, and therefore the data submission requirements applying to a specific FDC are unknown. ${ }^{17}$ Second, CDSCO can override data submission requirements. It has a wide power to dispense with the requirement to submit data 'if satisfied that there is adequate published evidence regarding the safety of the drug'. In 2005, a further discretion was added, allowing toxicological and clinical data requirements to be 'abbreviated, deferred or omitted' if the drugs addressed 'life threatening/serious diseases or diseases 
of special relevance to the Indian health scenario'. The Rules are silent on what constitutes the public interest, adequate published safety evidence and on what diseases are covered. The Rules do not require CDSCO to explain or make public its reasoning when exercising these discretions, and no public information is systematically made available as to whether they have exercised them. Third, the regulator does not publish or summarise the clinical evidence submitted to it or its evaluation of that evidence.

\section{Guidance from CDSCO}

There appears to be no finalised guidance on FDCs published by CDSCO.

Its website contains a draft document entitled 'Guidance for Industry on Fixed Dose Combinations', dated April 2010, 'for feedback purposes only. Comments and suggestions regarding this draft document should be submitted within 30 days of publication'. ${ }^{18}$ The document focuses on the forms and payments that drug companies must use and make and contain little substantive guidance beyond reiterating the rules, and do not use the same FDC categories as those set out in Appendix VI of Schedule $\mathrm{Y}^{15}$ The CDSCO website also contains a document entitled 'System of preliminary scrutiny by CDSCO at the time of receipt of application for approval of Fixed Dose Combinations', which is stated to be effective from 1 January 2011 but contains little substantive content. ${ }^{19}$

\section{WHO guidelines}

In 2005, the WHO adopted its guidelines for registration of fixed-dose medicinal products 'intended to provide advice to those countries that do not, as yet, have guidelines for this type of product' (see online supplementary figure 1) ${ }^{20}$ While India has had FDC-specific rules since 1988 , as well as draft industry guidance and a preliminary scrutiny document, the WHO guidelines are more extensive, substantive and clearly drafted. They contain a set of 'general principles' applying to clinical efficacy and safety evidence and assessment, which do not appear in the Indian Rules or administrative documents.

\section{GATHERING THE CLINICAL TRIALS EVIDENCE}

We previously reported PharmaTrac data of the five top-selling metformin FDCs in India for the 12-month period of November 2011 to October 2012. ${ }^{21}$ The following were the resulting five top-selling metformin FDCs: (1) glimepiride/metformin, (2) glimepiride/ pioglitazone/metformin, (3) glipizide/metformin, (4) glibenclamide/metformin, and (5) gliclazide/ metformin. Although all five of these top-selling formulations were approved by CDSCO, three of these, glimepiride/metformin, glimepiride/pioglitazone/ metformin and gliclazide/metformin, were launched on the market prior to CDSCO approval (figure 1). ${ }^{4} \mathrm{PubMed}$ and Embase databases and the Cochrane Library were searched from 1 January 1980 to 1 April 2016 for all published clinical trials on patients with type 2 diabetes investigating the five top-selling FDCs (see online supplementary figures 2 and 3). After application of inclusion/ exclusion criteria, 25 publications remained eligible for inclusion: 3 of glimepiride/metformin, 2 of glimepiride/ pioglitazone/metformin, 1 of glipizide/metformin, 19 of glibenclamide/metformin and none of gliclazide/ metformin (online supplementary figures 4 and 5 and tables 2, 3 and 4 illustrate the results of the search strategy for unpublished trials and detail the 16 retrieved unpublished trials).

Overall, 23 of the 29 separate comparator arms (from 25 trials) examined glibenclamide/metformin; three, glimepiride/metformin; two, glimepiride/pioglitazone/ metformin; one, glipizide/metformin; none, gliclazide/ metformin. In order to assist in the analysis, we grouped them into six categories of comparator arms: (1) FDC versus concomitant treatment with the FDC components given as SDFs; (2) FDC versus monotherapy with one of the components; (3) FDC versus a different FDC combination or concomitant SDF diabetes treatment; (4) FDC versus FDC with the same components but comparing different dosages or formulations (ie, dose 1 vs dose 2); (5) other (eg, same FDC in the same dosage/formulation but under fed versus fasting conditions or no comparator); and (6) new FDC formulation versus previously marketed FDC (table 2). Only one trial compared an FDC (glibenclamide/metformin) versus concomitant treatment with glibenclamide and metformin. ${ }^{22}$ It was a 2-week trial in 40 patients by an MNC, which evaluated glucose levels (not haemoglobin A1c (HbA1c)) but not adverse events. The trial was inadequately powered and was too short to support a robust evaluation of efficacy or safety of the FDC.

Only three clinical trials of metformin FDCs on patients with type 2 diabetes were conducted in India. One was a trial of 28 patients of 3-month duration and two other trials included 101 patients comparing the FDC glimepiride/pioglitazone/metformin with metformin plus insulin or no treatment. ${ }^{23-25}$

\section{WEIGHING THE CLINICAL TRIALS EVIDENCE}

Because CDSCO's rules governing the approval of FDCs in India provide a great deal of latitude and have been weakened over time, we used the WHO's 2005 Technical Report, Guidelines for Registration of Fixed-Dose Combination Medicinal Products, which was intended to provide guidance to drug regulatory agencies on robust registration requirements for FDCs given their growing use in treating diseases such as HIV, malaria and tuberculosis (see online supplementary figure 1 ).$^{20}$ On the basis that diabetes is highly prevalent in India and affects millions of people, treatment is long term, and risks of hypoglycaemia and poor tolerance are well-reported, we adopted four criteria which we considered are generally necessary for evaluating the safety and efficacy evidence derived from clinical trials, relating to the size, duration, design and adverse reactions: 
Table 2 Categories of comparator arms in 42 published and unpublished clinical trials of metformin FDCs in patients with type 2 diabetes.

\begin{tabular}{|c|c|c|c|c|c|c|c|}
\hline \multirow[b]{2}{*}{ Metformin FDC } & \multirow[b]{2}{*}{$\begin{array}{l}\text { Published/ } \\
\text { Unpublished }\end{array}$} & \multicolumn{6}{|c|}{ Categories of comparator arms } \\
\hline & & $\begin{array}{l}\text { FDC vs concomitant } \\
\text { SDFs* }\end{array}$ & $\begin{array}{l}\text { FDC vs } \\
\text { monotherapy }\end{array}$ & $\begin{array}{l}\text { FDC vs } \\
\text { other }\end{array}$ & $\begin{array}{l}\text { FDC vs } \\
\text { FDC }\end{array}$ & Otherף & $\begin{array}{l}\text { Experimental } \\
\text { vs marketed** }\end{array}$ \\
\hline \multirow{2}{*}{$\begin{array}{l}\text { Glimepiride } \\
\text { CDSCO approval } 2002\end{array}$} & Published & 0 & 1 & 2 & 0 & 0 & 0 \\
\hline & Unpublished & 0 & 5 & $1 \dagger+$ & $3+†$ & 3 & 1 \\
\hline \multirow{2}{*}{$\begin{array}{l}\text { Glimepiride/Pioglitazone } \\
\text { CDSCO approval } 2005\end{array}$} & Published & 0 & 0 & 1 & 0 & 1 & 0 \\
\hline & Unpublished & 0 & 0 & $3+†$ & $2 \dagger \dagger$ & 0 & 0 \\
\hline \multirow{2}{*}{$\begin{array}{l}\text { Glipizide } \\
\text { CDSCO approval } 1998\end{array}$} & Published & 0 & 1 & 0 & 0 & 0 & 0 \\
\hline & Unpublished & 0 & 0 & 0 & 0 & 0 & 0 \\
\hline \multirow{2}{*}{$\begin{array}{l}\text { Glibenclamide } \\
\text { CDSCO approval } 1995\end{array}$} & Published & 1 & 8†† & 6 & $7 \dagger+$ & 0 & 1 \\
\hline & Unpublished & 0 & 1 & 1 & 0 & 0 & 0 \\
\hline \multirow{2}{*}{$\begin{array}{l}\text { Gliclazide } \\
\text { CDSCO approval } 2005\end{array}$} & Published & 0 & 0 & 0 & 0 & 0 & 0 \\
\hline & Unpublished & 0 & 0 & 0 & 0 & 0 & 0 \\
\hline
\end{tabular}

Online supplementary tables 3 and 4 provide details of the unpublished trials.

${ }^{*}$ FDC versus concomitant SDFs=FDC versus concomitant treatment with the FDC components given as SDFs.

†FDC versus monotherapy=FDC versus metformin and/or sulfonylurea monotherapy.

\#FDC versus other=FDC versus a different FDC combination or concomitant treatment.

$\S F D C$ versus FDC=sameFDC components but comparing different dosages or formulations.

\Other=same FDC but under different trial conditions, for example, fed versus fasting conditions.

${ }^{\star \star}$ Experimental versus marketed=experimental (new) FDC versus previously marketed FDC.

††Trials (7) with multiple comparator arm categories in the same study.

CDSCO, Central Drugs Standard Control Organization; FDC, fixed-dose combinations; SDF, single-drug formulations.

- Size: the WHO’s International Clinical Trials Registry Platform describes efficacy studies as being conducted in 'large groups' of people 'from several hundred to several thousand'.

- Duration: the WHO guidelines state the minimum trial duration, if the FDC is intended for long-term use, is 6 months.

- Design: the WHO guidelines ask whether the combination has an advantage over the individual components.

- Adverse reactions: the WHO guidelines advocate the benefits should outweigh the potential adverse events.

We determined whether (1) there was a significant difference in the study outcome for the FDC over the comparator treatment, (2) the proportions of participants on the FDC experiencing adverse events or symptoms of hypoglycaemia were reported, (3) the study had balanced the advantages and disadvantages of the FDC over the comparator treatment, and (4) evidence and argument were presented to show that benefits outweighed potential adverse events. ${ }^{20} 26$

None of the 25 published clinical trials met all four selected WHO FDC criteria (table 3; see online supplementary table 2). Table 3 shows each published trial against the WHO approval criteria for sample size, study duration, study design and that benefits should outweigh potential adverse events. For sample size, only 8 of the 25 trials met our minimum number of subjects criterion of greater than 300 subjects and only 2 had more than 500 subjects. Ten of the 25 trials met the minimum duration criterion of 6 months; only 4 were of 12-month duration.
Of these only three met both the minimum number of subjects and minimum duration. ${ }^{27-29}$

Of the 25 trials, only one had been designed to show advantage over individual components. The single trial comparing the metformin/glibenclamide FDC with metformin and glibenclamide used concomitantly as SDFs among 40 patients over 2 weeks found lower 2-hour postprandial glucose levels with the FDC, but the difference was not significant. ${ }^{22}$ Ten trials published data demonstrating each drug contributed to an overall advantage of the FDC over individual components by comparing the FDC with monotherapy. Of the remaining 14 trials, 6 compared the FDC with another FDC, seven compared it with the same FDC at a different dosage or formulation, and one compared the FDC with a previously marketed FDC. To determine whether retrieved trials had presented a suitable argument for balancing the advantages and disadvantages of using an FDC over a standard oral hypoglycaemic treatment, we looked at the change in HbAlc versus the comparator arm, reported adverse events and incidents of hypoglycaemia to determine if an explanation of a balance of advantages and disadvantages was presented, and if a balance of harms and benefits of the experimental treatment was taken into account. Of the 25 trials, 14 reported a significant decrease in HbA1c levels with a metformin FDC versus monotherapy. Thirteen trials reported both frequency of adverse events and symptoms of hypoglycaemia specifically for the FDC. Five studies reported adverse events or hypoglycaemia in aggregate but did not distinguish between treatment arms. Six studies did not report these 


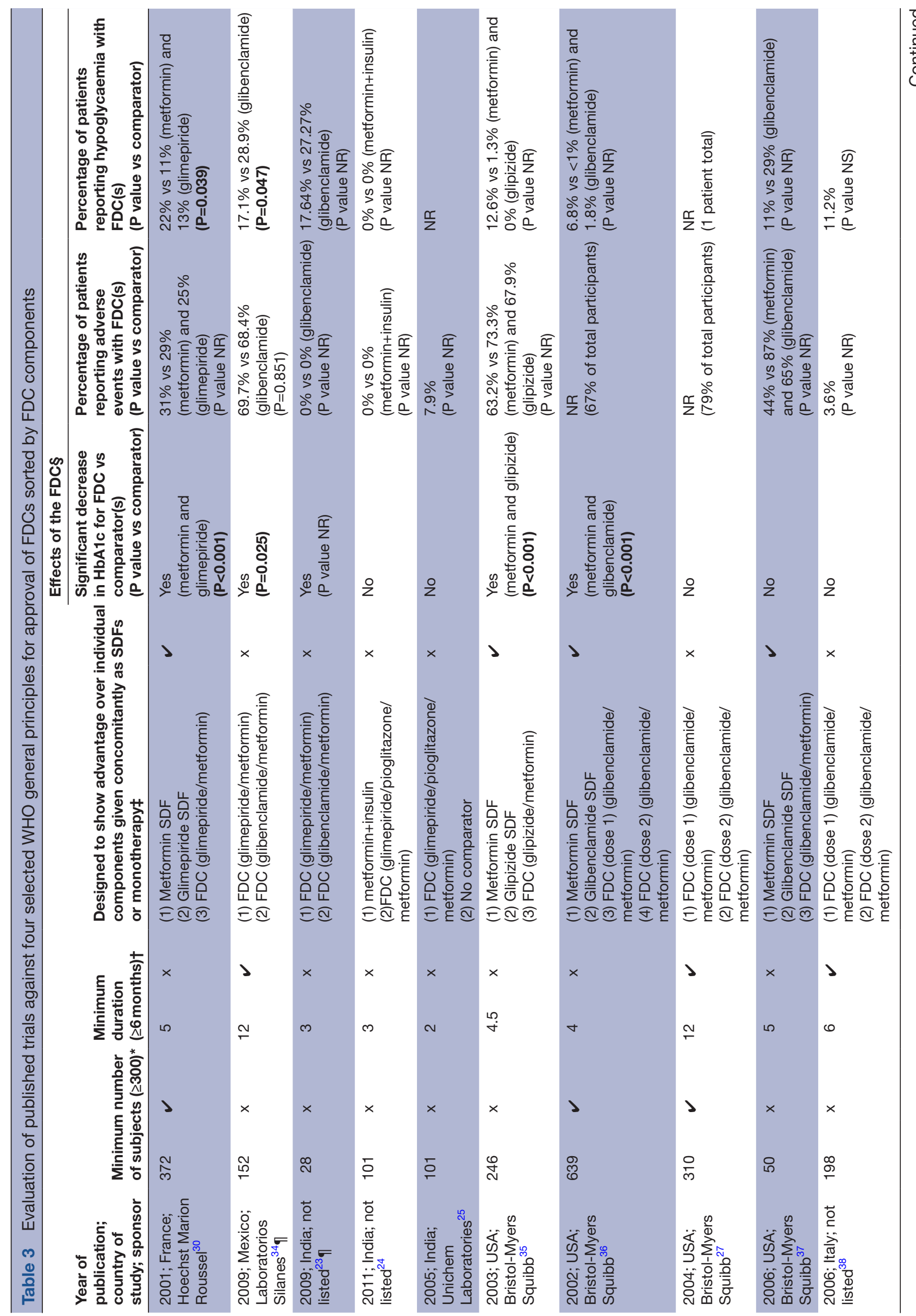

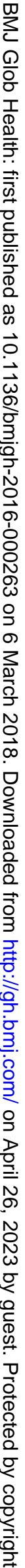




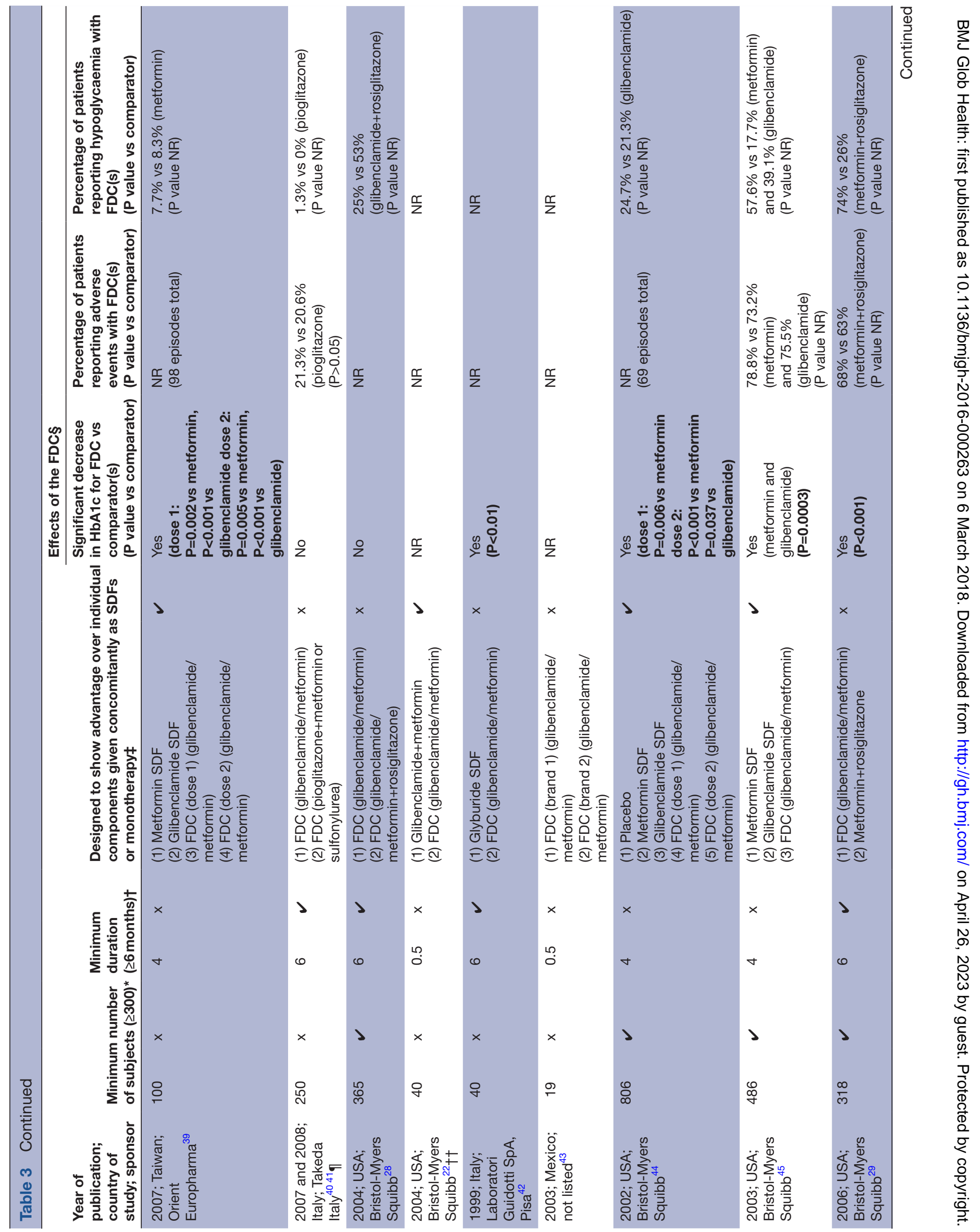




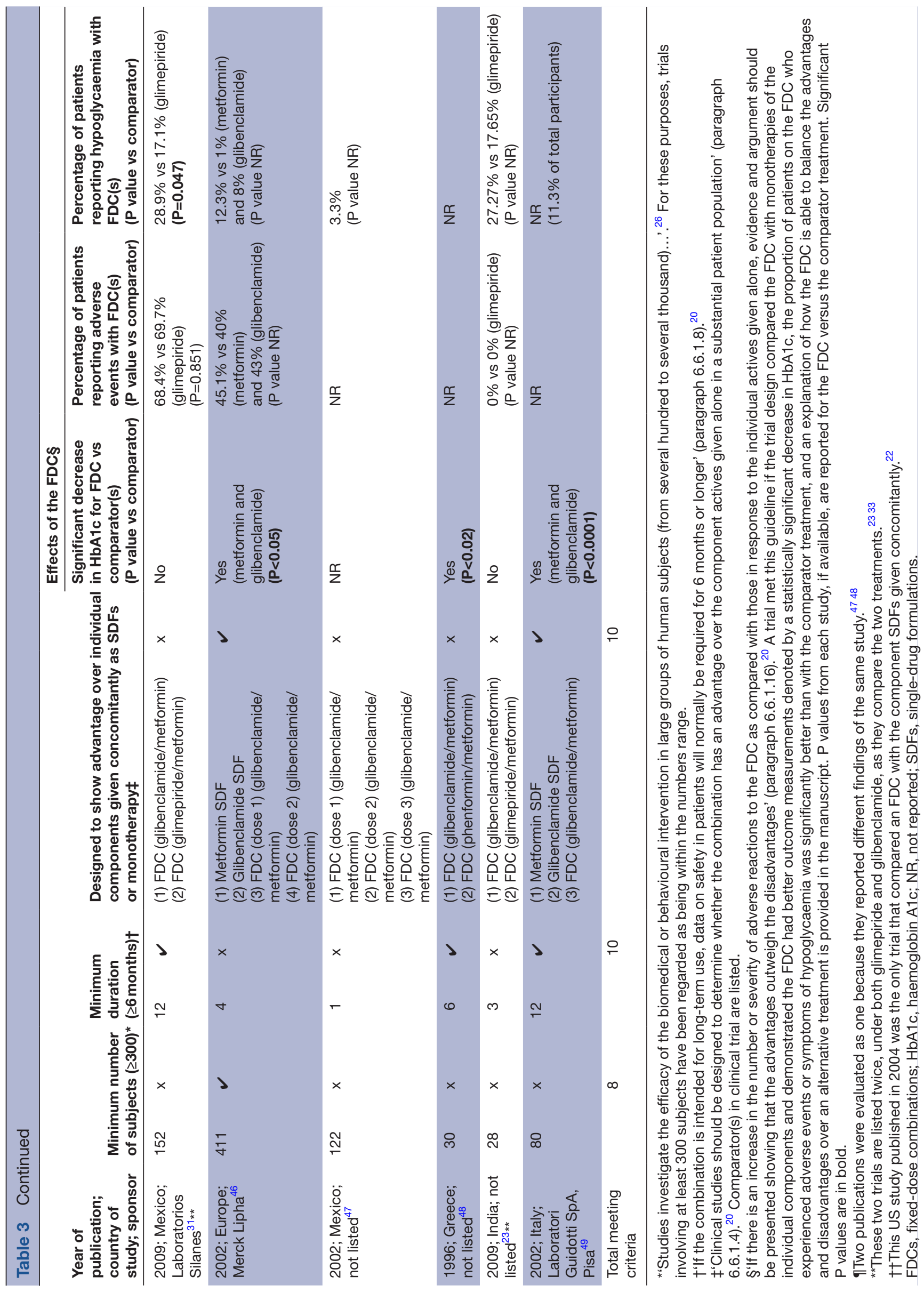

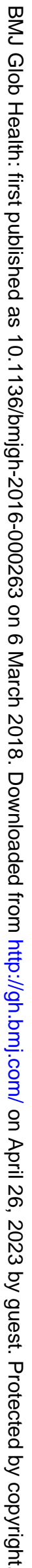


outcomes and six studies only reported one of the two outcomes. In five trials more than $50 \%$ of participants experienced adverse events with FDCs; these were not statistically significant (or not reported) compared with the alternate treatment regimen(s). Three trials reported increased patient compliance as the explanation of benefit for the FDC over the comparator treatment. ${ }^{22} 2427$ However only one of these studies compared the FDC with concomitant treatment but did not report other supportive outcomes (ie, HbAlc levels, adverse events, hypoglycaemia). ${ }^{22}$ No studies balanced benefits and harms, that is, adverse reactions and clinical outcomes. Additional information on reported safety and efficacy for published trials is presented in online supplementary table 2. Overall, no trials provided enough evidence of safety and efficacy to justify the use of the FDC over concomitant treatments of the same active ingredients.

\section{LACK OF CLINICAL TRIAL EVIDENCE FOR METFORMIN FDCS IN INDIA}

None of the published trials included in this review met all four WHO-based criteria (table 3). Despite rigorous searching, we found only one study evaluating the efficacy and safety of a metformin FDC versus concomitant use of the component drugs as SDFs; it was underpowered and of poor quality. ${ }^{23}$ Most studies only compared metformin FDCs with monotherapies. Overall, more than half of the published trials were conducted in the USA, while only three were conducted in India. Only two trials were published prior to CDSCO approval (glimepiride and glimepiride/pioglitazone), of which only one study was conducted on Indian patients prior to its launch in India. ${ }^{25}{ }^{30}$ The Indian study evaluated the efficacy of the FDC in just 101 patients with type 2 diabetes over 2 months of treatment. ${ }^{25}$

The overall lack of publicly available India-specific data heightens the need for publication of unpublished trials with Indian patients (see online supplementary table 2). India has only required registration with Clinical Trials Registry - India, the national clinical trials database, since 2009. Although unpublished trials are listed in the clinical trial registries, they only provide basic trial information with no results or outcomes reported (see online supplementary table 3 ). Both national and international databases of clinical trials should be updated routinely. The lack of trials on Indian patients, in particular, is of concern considering CDSCO's guidelines for FDC approvals acknowledge the importance of conducting trials on the Indian population to determine safety and efficacy.

The use of FDCs for treatment of diabetes has been described as an Indian innovation. ${ }^{31}$ Indeed, sales data show that hundreds of brands of metformin FDCs are on the market in India and outstrip sales of metformin SDFs in terms of both volume and value. ${ }^{421}$ India, therefore, should be at the forefront of regulatory practices. Although stringent pharmaceutical regulatory systems should be in place to protect patients from potentially dangerous medicines, as well as ensure the medicines are effective for the condition being treated, the recent overturning of the government ban on irrational FDCs raises serious questions about the strength of the rules on clinical trials evidence. According to the WHO, FDCs that contain (1) the same active ingredients, (2) in the same doses, (3) as an established regimen of single drugs, (4) with the same dosage regimen, (5) a well-characterised efficacy and safety profile and (6) where the products used in obtaining clinical relevant outcomes have been shown to be of good quality need not 'usually' be trialled. However, given that none of the evaluated published trials provide such evidence, CDSCO should demonstrate how it considers efficacy and safety to have been established. Although it is possible that CDSCO holds reliable evidence supporting metformin FDC approvals and knows the results of the unpublished trials, as is common with regulatory agencies, it should make the evidence and the trial results publicly available.

Our examination of published and unpublished studies of metformin FDCs for type 2 diabetes raises serious questions about the basis of CDSCO approvals as it shows the lack of trial evidence to support the efficacy and safety of the top-selling metformin FDCs approved for marketing, manufacture and sale in India. FDC treatments for diabetes are not recommended by national or international treatment guidelines, yet many metformin FDCs have been approved by CDSCO. In addition, dozens of manufacturers have been licensed by individual States, but as public details of licences are not published we could not explore this further. The finding that three of the five top-selling metformin FDC formulations were launched on the market before CDSCO approval highlights weaknesses in the regulatory processes of both the federal system and the State regulators.

Furthermore, four out of five of these top-selling FDCs were found to be on the list of banned FDCs by the Ministry of Health and Family Welfare from March 2016 (see online supplementary table 1 ). ${ }^{2}$ Hundreds of manufacturers, including many MNCs, petitioned State courts for a stay on the ban. In December 2016 they succeeded. The Delhi High Court lifted the ban giving companies the ability to reintroduce potentially harmful medicines into the market-place. ${ }^{32}$ This ruling was upheld by the Supreme Court in December 2017 when remitting the matter for the consideration of the Drugs Technical Advisory Board.

MNCs have played a significant role in the clinical trials of metformin FDCs. Eighteen of the 25 published clinical trials conducted in patients with type 2 diabetes disclosed sponsor funding or were conducted by pharmaceutical companies. Eight different companies were represented as sponsors in the trials, with nine studies sponsored by MNCs. The poor quality of available published trials and their funding sources raise concerns about the motivation for conducting these trials and whether the sponsors 
are using them for seeding or marketing purposes to gain a foothold in country markets. ${ }^{33}$

\section{CONCLUSION}

To our knowledge, this is the first study analysing the availability of published clinical trials evidence on the efficacy and safety of metformin FDCs. Our examination exposes serious deficiencies in the evidence base for metformin FDCs for type 2 diabetes and raises questions about the role of MNCs in manufacturing these for sale and use. To justify metformin FDC approvals and provide confidence in their efficacy and safety, CDSCO should make public the evidence it used in approving the metformin FDCs examined in this review. If that evidence does not extend beyond the trials reviewed here, those FDCs should be banned immediately. If that evidence includes the results of trials not reviewed in this paper, which do not meet the four WHO standards used for evaluation, those FDCs should be banned. Mitigation of any public health consequences of removing widely used diabetes treatments from the market will require collaboration between the regulators, providers as well as drug manufacturers, to ensure that the medicines in the market-place have proven efficacy and safety. It is also necessary for clinical trial databases to be constantly updated with both protocol and outcomes in order to improve transparency of trial data, and for the evidence underpinning drug approvals to be published. Legislation setting out clinical trial requirements for new drugs should be revised to prevent irrational FDCs from entering the market. The government's March 2016 ban on FDCs should be reinstated and a statutorily-required review of FDCs established, similar to the one mandated by the US Congress in 1962.

Acknowledgements The authors wish to thank Patricia McGettigan and Petra Sevcikova for critical review of the manuscript.

Contributors AMP conceived the study. PR contributed to the portion of the manuscript regarding regulation. VE conducted the literature search and data extraction, and drafted the manuscript. All authors contributed to the analysis, review, and drafting of the manuscript and approval of the final submission.

Funding This report results from a research funded by the European Union Seventh Framework Programme Theme: Health 4200944.3.242 (grant no 242 262) under the title Access to Medicines in Africa and South Asia (AMASA). The project team includes partners at the Swiss Tropical and Public Health Institute at the University of Basel (Switzerland), University of Edinburgh (UK), Queen Mary University of London (UK), University of Ghent (Belgium), Makerere University (Uganda), Mbarara University of Science and Technology (Uganda), University of the Western Cape (South Africa), and the Foundation for Research in Community Health (India).

\section{Competing interests None declared.}

Provenance and peer review Not commissioned; externally peer reviewed.

Data sharing statement Clinical trial data presented in this paper are publicly available through publications or clinical trial databases. PharmaTrac data can be obtained by contacting AIOCD Pharmasofttech AWACS Pvt. Ltd. directly.

Open Access This is an Open Access article distributed in accordance with the Creative Commons Attribution Non Commercial (CC BY-NC 4.0) license, which permits others to distribute, remix, adapt, build upon this work non-commercially, and license their derivative works on different terms, provided the original work is properly cited and the use is non-commercial. See: http://creativecommons.org/ licenses/by-nc/4.0/ (c) Article author(s) (or their employer(s) unless otherwise stated in the text of the article) 2018. All rights reserved. No commercial use is permitted unless otherwise expressly granted.

\section{REFERENCES}

1. U.S. Food and Drug Administation. Novel drug approvals. http:// www.fda.gov/Drugs/DevelopmentApprovalProcess/Druglnnovation/ default.htm (accessed 08 Jul 2016).

2. Ministry of Health and Family Welfare, Department of Health and Family Welfare. Gazette of India, 10 March 2016. New Delhi, 2016. http://www.cdsco.nic.in/writereaddata/GSR705E.pdf (accessed 08 Jul 2016).

3. McGettigan P, Mahajan R, Kadam A, et al. Regulatory upheaval and irrational medicines in India: a study of fixed dose combination drugs. PLoS Med 2015;12:e1001826.

4. Evans V, Pollock AM. The proliferation of irrational metformin fixed-dose combinations in India. Lancet Diabetes Endocrinol 2015;3:98-100.

5. Economic Times. 26 new drugs permitted for sale without trials in India. 18 August 2013. http://articles.economictimes.indiatimes. com/2013-08-18/news/41422720_1_clinical-trials-drug-trials-drugsstandard-control-organisation (accessed 08 Jul 2016)

6. Times of India. India is the diabetes capital of the world. 28 January 2016. http://timesofindia.indiatimes.com/life-style/health-fitness/ health-news/India-is-the-diabetes-capital-of-the-world/articleshow/ 50753461.cms. (accessed 08 Jul 2016).

7. Supreme Court of India. Civil Appellate Jurisdiction. Civil Appeal NO. 22972 of 2017. http://supremecourt.gov.in/supremecourt/ 2017/3271/3271_2017 Judgement_15-Dec-2017.pdf (accessed 11 Jan 2018).

8. Delhi High Court. W.P.(C) No.2212/2016. Date of Decision: 01 December 2016. http://lobis.nic.in/ddir/dhc/RSE/judgement/01-122016/RSE01122016CW22122016.pdf (accessed 06 Feb 2016).

9. Pan F, Chernew ME, Fendrick AM. Impact of fixed-dose combination drugs on adherence to prescription medications. J Gen Intern Med 2008;23:611-4

10. Schernthaner G. Fixed-dose combination therapies in the management of hyperglycaemia in Type 2 diabetes: an opportunity to improve adherence and patient care. Diabet Med 2010;27:739-43.

11. Vittorino Gaddi A, Benedetto D, Capello F, et al. Oral antidiabetic therapy in a large Italian sample: drug supply and compliance for different therapeutic regimens. Public Health 2014;128:70-6.

12. Cheong $\mathrm{C}$, Barner JC, Lawson KA, et al. Patient adherence and reimbursement amount for antidiabetic fixed-dose combination products compared with dual therapy among Texas Medicaid recipients. Clin Ther 2008;30:1893-907.

13. Dailey G, Kim MS, Lian JF. Patient compliance and persistence with anti-hyperglycemic therapy: evaluation of a population of type 2 diabetic patients. J Int Med Res 2002;30:71-9.

14. Melikian C, White TJ, Vanderplas A, et al. Adherence to oral antidiabetic therapy in a managed care organization: a comparison of monotherapy, combination therapy, and fixed-dose combination therapy. Clin Ther 2002;24:460-7.

15. Central Drugs Standard Control Organization. Drugs and Cosmetics Rules 1945, Schedule Y. http://cdsco.nic.in/html/D\&C_Rules_ Schedule Y.pdf (accessed 02 Jun 2017).

16. Roderick P, Mahajan R, McGettigan P, et al. India should introduce a new Drugs Act. Lancet 2014;383:203-6.

17. Central Drugs Standard Control Organization. Fixed Dose Combinations Approved by DCG(I) Since 1961 till 30th June 2017. http://cdsco.nic.in/writereaddata/latesapproved\%20FDC\%20list\% 20till\%2030\%20june\%202017.pdf (accessed 11 Jul 2017).

18. Central Drugs Standard Control Organization. Guidance for Industry on Fixed Dose Combinations (FDCs), April 2010. http://www.cdsco. nic.in/writereaddata/FDC\%20Guidelines\%20_\%20Revised1.pdf (accessed 11 Jul 2017).

19. Central Drugs Standard Control Organization. System of preliminary scrutiny by CDSCO at the time or receipt of application for approval of Fixed Dose Combinations (FDCs). http://www. cdsco.nic.in/writereaddata/Fixed\%20dose\%20Combin.pdf (accessed 11 Jul 2017)

20. World Health Organization. Guidelines for registration of fixed-dose combination medicinal products - Annex 5. WHO Technical Report Series, No. 929. Geneva: World Health Organization, 2005.

21. PharmaTrac. Sales and volume data, 2012.

22. Donahue SR, Turner KC, Patel S. Pharmacokinetics and pharmacodynamics of glyburide/metformin tablets (Glucovance) versus equivalent doses of glyburide and metformin in patients with type 2 diabetes. Clin Pharmacokinet 2002;41:1301-9. 
23. Shimpi RD, Patil PH, Kuchake VG, et al. Comparison of effect of metformin in combination with glimepiride and glibenclamide on glycaemic control in patient with Type 2 diabetes mellitus. Int $J$ PharmTech Res 2009;1:50-61.

24. Bell DS, Dharmalingam M, Kumar S, et al. Triple oral fixeddose diabetes polypill versus insulin plus metformin efficacy demonstration study in the treatment of advanced type 2 diabetes (TrIED study-II). Diabetes Obes Metab 2011;13:800-5.

25. Meshram DM, Langade DG, Kinagi SB, et al. Evaluation of efficacy and safety of fixed dose combination of glimepiride 2 $\mathrm{mg}$ pluspioglitazone $15 \mathrm{mg}$ plus metformin SR $500 \mathrm{mg}$ in the management of patients with type-2 diabetes mellitus. J Indian Med Assoc 2005;103:447-50.

26. World Health Organization. International Clinical Trials Registry Platform (ICTRP) - Glossary. Geneva: World Health Organization, 2013. http://www.who.int/ictrp/glossary/en/ (accessed $08 \mathrm{Jul} 2016$ )

27. Blonde L, Joyal S, Henry D, et al. Durable efficacy of metformin/ glibenclamide combination tablets (Glucovance) during 52 weeks of open-label treatment in type 2 diabetic patients with hyperglycaemia despite previous sulphonylurea monotherapy. Int J Clin Pract 2004;58:820-6.

28. Dailey GE, Noor MA, Park JS, et al. Glycemic control with glyburide/ metformin tablets in combination with rosiglitazone in patients with type 2 diabetes: a randomized, double-blind trial. Am J Med 2004;116:223-9.

29. Garber A, Klein E, Bruce S, et al. Metformin-glibenclamide versus metformin plus rosiglitazone in patients with type 2 diabetes inadequately controlled on metformin monotherapy. Diabetes Obes Metab 2006;8:156-63.

30. Charpentier G, Fleury F, Kabir M, et al. Improved glycaemic control by addition of glimepiride to metformin monotherapy in type 2 diabetic patients. Diabet Med 2001;18:828-34.

31. Kalra S, Sahay BK, Rao MS. Fixed dose combinations in diabetes: Indian innovation, Indian pride. Indian J Endocrinol Metab 2012;16(Suppl1):4-5.

32. The Hindu. Delhi High Court reverses ban on combination drugs. 01 December 2016. http://www.thehindu.com/news/national/ article16735149.ece (accessed 6 Feb 2017).

33. Kessler DA, Rose JL, Temple RJ, et al. Therapeutic-class warsdrug promotion in a competitive marketplace. $N$ Engl J Med 1994;331:1350-3.

34. González-Ortiz M, Guerrero-Romero JF, Violante-Ortiz R, et al. Efficacy of glimepiride/metformin combination versus glibenclamide/ metformin in patients with uncontrolled type 2 diabetes mellitus. J Diabetes Complications 2009;23:376-9.

35. Goldstein BJ, Pans M, Rubin CJ. Multicenter, randomized, doublemasked, parallel-group assessment of simultaneous glipizide/ metformin as second-line pharmacologic treatment for patients with type 2 diabetes mellitus that is inadequately controlled by a sulfonylurea. Clin Ther 2003;25:890-903.

36. Blonde L, Rosenstock J, Mooradian AD, et al. Glyburide/metformin combination product is safe and efficacious in patients with type
2 diabetes failing sulphonylurea therapy. Diabetes Obes Metab 2002:4:368-75.

37. Bruce S, Park JS, Fiedorek FT, et al. Beta-cell response to metformin-glibenclamide combination tablets (Glucovance) in patients with type 2 diabetes. Int J Clin Pract 2006;60:783-90.

38. Brunetti P, Pagano G, Turco C, et al. Effects of two different glibenclamide dose-strengths in the fixed combination with metformin in patients with poorly controlled T2DM: a double blind, prospective, randomised, cross-over clinical trial. Diabetes Nutr Metab 2004;17:350-7.

39. Chien $\mathrm{HH}$, Chang CT, Chu NF, et al. Effect of glyburide-metformin combination tablet in patients with type 2 diabetes. J Chin Med Assoc 2007;70:473-80.

40. Comaschi M, Demicheli A, Di Pietro C, et al. Effects of pioglitazone in combination with metformin or a sulfonylurea compared to a fixed-dose combination of metformin and glibenclamide in patients with type 2 diabetes. Diabetes Technol Ther 2007;9:387-98.

41. Comaschi M, Corsi A, Di Pietro C, et al. The effect of pioglitazone as add-on therapy to metformin or sulphonylurea compared to a fixed-dose combination of metformin and glibenclamide on diabetic dyslipidaemia. Nutr Metab Cardiovasc Dis 2008;18:373-9.

42. Erle G, Lovise S, Stocchiero C, et al. A comparison of preconstituted, fixed combinations of low-dose glyburide plus metformin versus high-dose glyburide alone in the treatment of type 2 diabetic patients. Acta Diabetol 1999;36:61-5.

43. Flores-Murrieta FJ, Aguilar-Cota ME, Camacho A, et al. Comparative bioavailability of two oral formulations manufactured in Mexico containing glyburide and metformin in diabetic patients. Proc West Pharmacol Soc 2003;46:82-4.

44. Garber AJ, Larsen J, Schneider SH, et al. Simultaneous glyburide/ metformin therapy is superior to component monotherapy as an initial pharmacological treatment for type 2 diabetes. Diabetes Obes Metab 2002;4:201-8.

45. Garber AJ, Donovan DS, Dandona P, et al. Efficacy of glyburide/ metformin tablets compared with initial monotherapy in type 2 diabetes. J Clin Endocrinol Metab 2003;88:3598-604.

46. Marre M, Howlett $\mathrm{H}$, Lehert $\mathrm{P}$, et al. Improved glycaemic control with metformin-glibenclamide combined tablet therapy (Glucovance) in Type 2 diabetic patients inadequately controlled on metformin. Diabet Med 2002;19:673-80.

47. Medina Santillán R, Reyes-García G, Mateos-García E. Metformin plus glyburide combination as therapy in failure to monotherapy in type 2 diabetic patients: one month follow-up. Proc West Pharmacol Soc 2002;45:139-40.

48. Raptis AE, Tountas NB, Yalouris AG, et al. Therapeutic effect of glibenclamide in a fixed combination with metformin or phenformin in NIDDM patients. Horm Metab Res 1996;28:89-94.

49. Tosi F, Muggeo M, Brun E, et al. Combination treatment with metformin and glibenclamide versus single-drug therapies in type 2 diabetes mellitus: a randomized, double-blind, comparative study. Metabolism 2003;52:862-7. 